\title{
The Development of the Masters' Professional Competence by Means of the Information and Communication Technologies
}

\author{
Moldabek Kulakhmet ${ }^{1}$, Alfira Hajrullina ${ }^{2}$, Nataliya Oleksiuk ${ }^{3}$, Miroslav Tvrdon ${ }^{4} \&$ Oksana Protas $^{5}$ \\ ${ }^{1}$ Silkway international University, Shymkent, Kazakhstan \\ ${ }^{2}$ Yelabuga Institute of the Kazan (Volga region) Federal University, Elabuga, Russia \\ 3 Ternopil National Volodymyr Hnatyuk Pedagogical University, Ternopil, Ukraine \\ ${ }^{4}$ Constantine the Philosopher University in Nitra, Nitra-Chrenova, Slovakia \\ ${ }^{5}$ Vasyl Stefanyk Precarpathian National University, Ivano-Frankivsk, Ukraine \\ Correspondence: Moldabek Kulakhmet, Silkway international University, Tokaev str., 27, Shymkent, 160000, \\ Kazakhstan. E-mail: mkulakhmet@inbox.ru
}

Received: October 12, 2020

doi:10.5430/ijhe.v10n1p226
Accepted: November 3, 2020

Online Published: November 6, 2020

URL: https://doi.org/10.5430/ijhe.v10n1p226

\begin{abstract}
Summarizing the results of the theoretical and experimental research confirmed the probability of the leading principles of the general and partial hypotheses, proved the effectiveness of solving the set tasks and made it possible to formulate the conclusions.the pedagogical system of development of professional competence of Masters-translators by the means of information and communication technologies, characterized by functionality, complexity, openness, unity and at the same time comparative independence of the structural components, was modeled. The system covers five subsystems: targeted, conceptual and methodological, content, operational and technological, evaluating and efficient. The experimental verification of the effectiveness of the proposed pedagogical system revealed significant quantitative and qualitative changes: the majority of the students of the experimental groups after their studies were completed acquired a level of the professional competence development above satisfactory, in particular, a noticeable increase of students with an average and high level was recorded. The received results were the consequence of the effective author's pedagogical system and the model of development of professional competence of Masters-translators by the means of information and communication technologies, and therefore with the help of the created pedagogical conditions and educational and methodical support.
\end{abstract}

Keywords: professional competence, information and communication technologies, educational and methodical support, pedagogical system

\section{Introduction}

\subsection{Introduce the Problem}

In the conditions of an integration of Ukraine into European and world structures, the volume of translation and interpretation is significantly increasing, which causes a rise in the social demand for highly qualified translators who are able to perform translation activities at the professional level, both in writing and oral forms. The translation services market has undergone fundamental changes which are shown in technologization, virtualization, client orientation and the dominance of the "customer-translation company-translator" model affecting the professional work of a translator. Along with the translation knowledge, skills and abilities, information and communication technologies (ICT) have become actualized, without proper possession of which the successful professional self-realization of a translation specialist is impossible.

The use of ICT is of a particular importance in the professional training process in magistracy as they serve as the means of its intensification (Lester, S. (2014), Shen-Miller, D. S., Schwartz-Mette, R., Van Sickle, K. S., Jacobs, S. C., Grus, C. L., Hunter, E. A., \& Forrest, L. (2015)). Modern ICT cause noticeable changes not only in the professional activity of translators but also in their professional training. The entry of Ukraine into the European educational space requires the adaptation of professional training of specialists, including translation specialists, to the educational requirements and standards of Europe.

Within the framework of the European Master’s Training of translators EMT («European Master’s in Translation») 
(Torres-Simón, E., \& Pym, A. (2019)), which is a project of a partnership between the European Commission and higher educational institutions which train translators at Master's degree level, a quality label was approved, which is given to those university Masters' programs of translators' training which fully respect the agreed professional standards and market needs, in particular, introduce modern translation technologies into the training of translators. All this causes the necessity for the maximum technologization of the training process at the Master's level, where the technologies need not only to be studied within a separate specialized course, but also need to be introduced together with other subjects which are studied by students (in particular, prerequisite ones) (Bravenboer, D., \& Lester, S. (2016), DeGrande, H., Liu, F., Greene, P., \& Stankus, J. A. (2018)).

Therefore, at present there is an urgent need for theoretical rethinking and qualitative update of the development of the professional competence of Masters-translators by the means of ICT to contribute to the rapid adaptation of the future translators to professional activity and for their competitiveness at the translation service market.

\subsection{Literature Review}

Systematic analysis of the scientific and pedagogical literature, on the one hand, confirms the importance of the issue of professional training of future translators, and, on the other hand, proves that not all reserves have been used for its effective provision, in particular, there are no complex works on the development of professional competence of Masters-translators by the means of ICT, which needs proper study and reflection in pedagogical investigations (Mulder, M. (2014), Hachfeld, A., Hahn, A., Schroeder, S., Anders, Y., \& Kunter, M. (2015), Hakim, A. (2015)).

The need to solve the mentioned problems is caused by the contradictions identified in the process of scientific reflection, as the following:

in the context of needs of social demand between: the increasing requirements of the society to the level of professional competence of Masters-translators by ICT and the real state of readiness of Magistrates to fulfill their professional translation responsibilities (Tiselius, E., \& Hild, A. (2017)); the emergence of a larger number of ICT tools for translation and interpretation, the possession of which is required by the translation service market representatives and their inadequate implementation within the traditional professional training system of the Masters-translators (Numminen, O., Laine, T., Isoaho, H., Hupli, M., Leino-Kilpi, H., \& Meretoja, R. (2014));

in the context of the needs of pedagogical science between: the expectations of the society for qualitative changes in the system of training of Masters-translators according to the world standards and insufficient theoretical rethinking of this process in the higher educational institutions (HEI) (Huang, R., Su, H., \& Xu, S. (2014)); the objective need to build a scientifically proven pedagogical system for the development of the professional competence of Masters-translators by the means of ICT and the lack of the development of its methodological foundations (Robert, I. S., Remael, A., \& Ureel, J. J. (2017)); world tendency for informatization of the educational process in the Magistracy and its proper consideration in the educational practice (Rahman, M. H. (2014), Cuminatto, C., Baines, R., \& Drugan, J. (2017));

in the context of the needs of pedagogical practice between: dynamic development of the translation industry and imperfection of pedagogical and educational-methodical support for the development of professional competence of Masters-translators by the means of ICT (Gardulf, A., Nilsson, J., Florin, J., Leksell, J., Lepp, M., Lindholm, C., ... \& Johansson, E. (2016)); the necessity to create effective pedagogical conditions to ensure the successful development of the professional competence of Masters-translators by the means of ICT and traditional approaches to the organization of theoretical and practical training of Masters-translators (Li, X. (2018), Heydari, A., Kareshki, H., \& Armat, M. R. (2016)); requirements of the modern information society for the professionalism of Masters-translators and the imperfection of approaches to the selection and structuring of the content of their professional training (Tang, F., \& Li, D. (2017)).

\subsection{The Concept of the Research}

The main principles are due to the complex nature of the problem of development of the professional competence of Masters-translators by the means of ICT, which involve the realization of scientific search according to the three interconnected concepts (theoretical, methodological and methodical) which were taken as the bases of the realization of the leading idea and the fulfillment of the tasks of the research.

Theoretical concept identifies a system of general principles which are manifested in the formulation of the purpose of the concept and the disclosure of a complex of the initial conceptual principles, which allow to identify the leading theories and ideas that are taken as the bases of the process of development of professional competence of Masters-translators by the means of ICT, which allow to create a pedagogical system(legal and regulatory framework of the professional training of Masters-translators, principles of professional standards of the translation industry, 
philosophical principles of the theory of cognition, the concept of information society and informatization of the educational process in the higher school), and also represents the conceptual and categorical apparatus of research (definitions of basic phenomena and notions).

The methodological concept reveals the conceptual and methodological basis of the research, which reflects the integration of the fundamental scientific approaches; the core of the concept which contains a complex of regularities and general didactic, methodical, specific principles and semantically meaningful content of the concept, is implemented in the form of the created authorial pedagogical system of development of professional competence of Masters-translators by the means of ICT.

The methodical concept reflects the methodical principles of introduction (development of pedagogical conditions and educational and methodical support) and verification (carrying out the research and experimental work) of the effectiveness of the created pedagogical system of development of professional competence of Masters-translators by the means of ICT.

\subsection{State Hypotheses}

The conceptual framework of the research includes the following provisions.

1. Development of professional competence of masters-translators by means of ICT should take place in the context of requirements of the market of translation services, European educational documents on training of translators, normative-legal bases of professional training of master-translators, branch standards, features of professional training of future translators in the context of informatization of the educational process in the master's degree, and be based on a scientifically sound concept, the methodological basis of which is market orientation, competence, technology, personality, systemic and reflective approaches, and general didactic, methodological, and specific principles.

2. The concept of developing the professional competence of master translators by means of ICT is expedient to consider as integral set of elements in the aggregate of relations and communications between them, that is as pedagogical system which structure forms a number of interdependent and interconnected subsystems: target, conceptual-methodological, substantial, operational-technological, evaluative and effective. All key components of the pedagogical system are in a hierarchical relationship, the dominant role in which goals play, which motivate the choice of pedagogical conditions.

3. Practical implementation of the pedagogical system for the development of professional competence of masters-translators by ICT is based on the introduction of pedagogical conditions (use of ICT for translation and interpretation) (CAT tools, special equipment for simultaneous translation); updating the content of professional disciplines ("Translation Practice", "Fundamentals of professional skills of a translator", "Factors of successful employment of a translator in the specialty"); the development of the author's system of exercises for teaching written translation and simultaneous interpretation; the use of learning environment (Moodle platform) in the development of professional competence of master translators; improvement of diagnostic tools for measuring the level of development of professional competence of masters-translators; construction of educational and methodical complexes for teachers who carry out training of masters-translators), and also demands development of special educational and methodological support.

The leading principles of the concept are embodied in the general hypothesis of the study which is based on the assumption that the quality of the professional training of Masters-translators will significantly improve, if the training is organized on the basis of theoretically based and experimentally tested author's pedagogical system of the development of the professional competence of Masters-translators by the means of ICT, created according to the formulated conceptual bases, needs of translation services market and peculiarities of informatization of the educational process in the Magistration. The general hypothesis is specified in partial hypotheses, according to which the development of the professional competence of Masters-translators by the means of ICT becomes effective, if:

to ensure the development of the professional competence of Masters-translators by the means of ICT on the basis of the created and substantiated on the theoretical, methodological, methodical levels of the author's concept;

- $\quad$ to build, on the basis of the author's concept, a pedagogical system of the development of the professional competence of Masters-translators by the means of ICT and to visualize it in the form of a model;

to create and introduce the pedagogical conditions for the development of the professional competence of Masters-translators by the means of ICT into the educational process, which make the realization of the author's pedagogical system possible; 
- to define and scientifically substantiate the ways of assessment of the educational achievements of Masters-translators, criteria, indexes and levels of development of the professional competence of Masters-translators by the means of ICT;

- to develop and introduce the scientific and methodical support for the development of the professional competence of Masters-translators by the means of ICT into the educational process;

- to experimentally test the effectiveness of the author's pedagogical system of the development of the professional competence of Masters-translators by the means of ICT.

The purpose of the research is to theoretically substantiate the concept of the development of the professional competence of Masters-translators by the means of ICT and to create and experimentally test the pedagogical system of its implementation.

In accordance with the set goal, the following research objectives are formulated:

1) to find out the state of elaboration of the problem of developing the professional competence of masters-translators in pedagogical theory and practice;

2) to substantiate the structure of professional competence of masters-translators, criteria, indicators, and levels of its development;

3) to characterize the features of professional training of masters-translators in the context of informatization of the educational process in the master's degree;

4) to develop the concept of development of professional competence of masters-translators by means of ICT;

5) to substantiate pedagogical conditions of development of professional competence of masters-translators by means of ICT;

6) to model the pedagogical system of development of professional competence of masters-translators by ICT means and to experimentally check its efficiency;

7) to develop educational and methodological support for the development of professional competence of masters-translators by means of ICT.

\section{Method}

\subsection{Organization of the Research}

The work was carried out during 2013-2018 in three stages.

At the first stage(2013)-analytically-stating-the requirements of the modern translation services market were clarified; the state of the problem of the development of the professional competence of Masters-translators by the means of ICT was studied; the purpose, tasks, subject, object of the scientific search was outlined; the hypothesis was formulated; the professional training of translators in the context of informatization of the educational process in the Magistracy was investigated; the spectrum of ICT for the training of future translators was characterized; positive experience in the development of the professional competence of Masters-translators by the means of ICT was studied; methodological approaches, principles and conceptual bases of the development of the professional competence of Masters-translators by the means of ICT were substantiated; the professional competence of a translator and its components, criteria, indexes and levels were analyzed; pedagogical conditions and the system of development of the professional competence of Masters-translators by the means of ICT were substantiated.

At the second stage (2013-2017) - forming-experimental testing of the research hypothesis was performed, the effectiveness of the author's pedagogical system of development of the professional competence of Masters-translators by the means of ICT was studied.

At the third stage (2017-2018) - the final-the quantitative and qualitative analysis of the results of the forming stage of the experiment was carried out, the statistical processing of the experimental data was done, the conclusions and methodical recommendations on the development of the professional competence of Masters-translators by the means of ICT were formulated.

The developed Questionnaire for the use of cloud technologies in educational activities is presented in Appendix A.

\subsection{Experimental Base of the Research}

The study was conducted in the form of a natural vertical-horizontal experimental training which included 175 Masters-translators (154 girls and 21 young men aged from 19 to 22 years) of the English Department of the Faculty 
of Foreign Languages (specialty 035 "Philology", specialization "Germanic Languages and Literature (including translation)") of V.N. Karazin Kharkiv National University, which was selected as a key experimental base.

\subsection{Research Design}

To achieve the set goal, to solve the tasks and to check the hypothesis at different stages of the scientific search, the following research methods were used:

-theoretical-analysis of works on translation studies, methods of teaching translation and foreign languages, didactics, psychology, linguistics, psycholinguistics, educational documents, which made it possible to characterize the state of processing of the mentioned problem; synthesis, induction and deduction, abstraction, generalization, by the means of which the comparison of theoretical and practical approaches to understanding of concepts of development of the professional competence of Masters-translators was made; conceptualization, design and modeling, which made it possible to substantiate the author's concept of development of the professional competence of Masters-translators by the means of ICT, construction of the pedagogical system and development of its model;

-empirical-surveys, questionnaires to find out the needs of student, teachers and representatives of the translation services market, to determine the development level of the professional competence of Masters-translators; testing of students to identify the presence of the knowledge while introducing theoretical academic subjects; pedagogical monitoring of the development of the professional competence of Masters-translators with the use of ICT in the course of implementation of the developed practical modules and theoretical disciplines; a pedagogical experiment to study the effectiveness of the proposed pedagogical system; qualitative and quantitative analysis of the experimental data;

-methods of mathematical statistics - Student's t-test and criterion i $\psi_{*}$ - Fisher's angular transformation for processing of data of the pedagogical experiment, confirmation of correctness of its conducting, accuracy of the obtained results and reliability of the hypothese.

The theoretical significance of the study is to substantiate the theoretical and methodological foundations of the organization of professional training of masters-translators in higher education, ensuring its focus on the development of professional competence through ICT; in the classification of basic concepts that make up the scientific thesaurus of the conceptual and categorical apparatus of development of professional competence of masters-translators; theoretical interpretation of connections between subsystems of pedagogical system; in the interpretation of the essence of market-oriented, competence, technological, personality-activity, reflective, and systemic approaches to the development of professional competence of master translators by means of ICT; finding out the features of informatization of the process of training translators in the master's degree.

The practical significance of the results obtained is substantiated by the development of educational and methodological support for the development of professional competence of master translators by ICT, which covers educational and methodological complexes in the disciplines "Translation Practice", "Fundamentals of professional skills of a translator", "Factors of successful employment of a translator in the specialty", which include work programs, educational and methodical support aids (author's system of exercises for teaching written translation and simultaneous interpretation), teaching aids (manuals "Fundamentals of professional skills of a translator", "Simultaneous translation in the socio-political sphere", "Factors of successful employment of a translator in the specialty"), control and measuring materials (tasks for current, boundary, and final control). The main results of the study, its provisions, and conclusions can be used in the development of textbooks, manuals, EMC, curricula, and programs.

\section{Results}

\subsection{The Results of the Study and Their Analysis and Interpretation}

The organization and conduction of a pedagogical experiment within the framework of our study envisaged the solving of the following tasks:

1) to develop tests and to select from the authentic sources the texts for translation in order to establish the level of development of students' knowledge, skills and abilities;

2) to conduct a pre-experimental assessment to determine the reference level of development of the corresponding knowledge, skills and abilities of the investigated;

3) to organize training according to the developed practical modules and theoretical courses in order to determine the effectiveness of the proposed pedagogical system and the optimal variant of teaching methods(for practical modules "Modern Translation Technologies. Systems of Translation Automation" and «Modern Translation 
Technologies. Simultaneous Interpretation in the Socio-Political Scope");

4) to conduct a post-experimental assessment to determine the final level of development of the corresponding knowledge, skills and abilities of Masters-translators;

5) to conduct an anonymous questionnaire of students of the experimental groups in order to determine their subjective attitude to the proposed pedagogical system, as well as self-assessment of their own level of development of professional competence for qualitative analysis of the results of the experiment;

6) to process and interpret the quantitative results of the experiment in order to determine the effectiveness of the proposed pedagogical system and the optimal variant of the teaching methods for practical modules "Modern Translation Technologies. Systems of Translation Automation" and "Modern Translation Technologies. Simultaneous Interpretation in Socio-Political Scope";

7) to formulate the conclusions on the effectiveness of the developed pedagogical system and the optimal variant of the teaching methods for the practical modules "Modern Translation Technologies. Systems of Translation Automation" and "Modern Translation Technologies. Simultaneous Interpretation in Socio-Political Scope".

Before the training started, a pre-experimental questionnaire was conducted among all the students to identify the level of development of the attitudinal component (self-rating, the presence of confidence as a translation specialist, conformity assessment to the employers' requirements) which students evaluated according to a number of parameters on a five-point scale.

As it turned out, the dominant level of development of the attitudinal component of the students is satisfactory (53.71\% of the students). An average and high levels of development were demonstrated by $18.29 \%$ and $12.0 \%$ of the students respectively, and $12.0 \%$ of the students even had a low level. The assessment of every parameter of the questionnaire(acquisition of professionally important knowledge, the level of formation of skills and abilities in written, oral from the paper and oral sequential translation, obtained on previous courses, awareness of trends in the world and the market of translation services, possession of the industry standards, motivation to translation activity, confidence as a translator, conformity to the employers' requirements, the level of professional competence development, development of perception and mnemonic skills)ranges from 3.02-3.14 points that is at a satisfactory level.

\subsection{Experimental Training on the Module "Modern Translation Technologies. Translation Automation Systems"}

Conducting a pre-experimental assessment just before the start of classes made a little sense since before that the vast majority of students did not use translation automation systems. Some students, as they said, had made several attempts to master the mentioned systems, but had not had much success. Due to this situation, students did not have the developed skills to use translation automation systems before classes. That is why the pre-experimental assessment was conducted at the fourth lesson when the students had already mastered the basic functionality of translation automation systems.

The content of the pre-experimental assessment was the translation of an authentic text of the International Treaty on Human Rights «Second Optional Protocol to the International Covenant on Civil and Political Rights, aiming at the abolition of the death penalty». For the students who studied according to option A the mentioned agreement was divided into several parts: 1) for handwritten translation (fragment volume-1635 characters without spaces, execution time - 45 minutes, sample of the text is added in Appendix K.1);2) for a written translation using SDL Trados (fragment volume is 3225 characters without spaces, execution time - 45 minutes). Therefore, the pre-experimental assessment was fully performed during the fourth classroom lesson lasting for 90 minutes.

The results of the pre-experimental assessment are presented in Table 1. 
Table 1. Results of a handwritten translation and translation using translation automation systems (SDL Trados) from English into Ukrainian in a pre-experimental assessment in a group

\begin{tabular}{|c|c|c|c|c|c|c|c|}
\hline & & $\begin{array}{l}\text { Total penalty } \\
\text { points } \\
\text { (handwritten) }\end{array}$ & $\begin{array}{c}\text { Score } \\
\text { on a 5-point } \\
\text { scale for } \\
\text { handwritten } \\
\text { translation }\end{array}$ & $\begin{array}{l}\text { Learning rate } \\
\text { (handwritten) }\end{array}$ & $\begin{array}{c}\text { Total } \\
\text { penalty } \\
\text { points } \\
\text { (written } \\
\text { using } \\
\text { SDL } \\
\text { Trados) }\end{array}$ & $\begin{array}{l}\text { Score on a } \\
\text { 5-point } \\
\text { scale for } \\
\text { written } \\
\text { translation } \\
\text { using SDL } \\
\text { Trados }\end{array}$ & $\begin{array}{c}\text { Learning } \\
\text { rate } \\
\text { (written } \\
\text { using } \\
\text { SDL } \\
\text { Trados) }\end{array}$ \\
\hline 1 & Student 1 & 3,6 & 3,2 & 0,64 & 5,4 & 3,7 & 0,74 \\
\hline 2 & Student 2 & 1,7 & 4,4 & 0,88 & 4,9 & 3,8 & 0,76 \\
\hline 3 & Student 3 & 6 & 2,3 & 0,46 & 5,8 & 3,6 & 0,72 \\
\hline 4 & Student 4 & 2,9 & 3,6 & 0,72 & 4,5 & 3,9 & 0,78 \\
\hline 5 & Student 5 & 3,9 & 3 & 0,60 & 6 & 3,5 & 0,70 \\
\hline 6 & Student 6 & 8,3 & 1,8 & 0,36 & 10 & 2,5 & 0,50 \\
\hline 7 & Student 7 & 3,1 & 3,4 & 0,68 & 2,5 & 4,6 & 0,92 \\
\hline 8 & Student 8 & 2,9 & 3,6 & 0,72 & 5,2 & 3,8 & 0,76 \\
\hline 9 & Student 9 & 3,8 & 3,1 & 0,62 & 6 & 3,5 & 0,70 \\
\hline 10 & Student 10 & 1,3 & 4,6 & 0,92 & 3 & 4,5 & 0,90 \\
\hline 11 & Student 11 & 2,6 & 3,8 & 0,76 & 5 & 3,8 & 0,76 \\
\hline 12 & Student 12 & 9,6 & 1,6 & 0,32 & 8 & 3 & 0,60 \\
\hline \multicolumn{2}{|c|}{ Average value } & 4,14 & 3,1 & 0,64 & 5,53 & 3,68 & 0,74 \\
\hline
\end{tabular}

As shown in Table 1, only two students (Student 2 and Student 10) demonstrated a proper level of a handwritten translation displaying a learning rate of 0.88 and 0.92 respectively. Three students (Students 4,8 and 11) were able to exceed the low limit of the "satisfactory" grade: 0.72 for Students 4 and 8, 0.76 for Student 11 . The rest could not reach even this limit. Two students (Student 6 and Student 12) showed extremely low level, their learning rates were 0.36 and 0.32 respectively. An average learning rate in a handwritten translation was only 0.64 which is not too high, especially considering the three weeks of studies before writing the assessment.

However, it should be mentioned here that the students did not like the tasks to translate in a hand-written form, they repeatedly expressed their reluctance to write when it was possible to translate in the way the professional translators do it-on a computer and with the help of a modern translation automation system. Many students had such advanced computer-typing skills that they were able to type a translation much faster than to write it. The student with the lowest learning rate did not even manage to fully write by hand the text of the translation.

The situation with a written translation using the translation automation system (SDL Trados) looks much better. Firstly, it should be immediately noted that all the students in the group were able to correctly use the program options which they had learned during the first three classes. Everyone was able to successfully download the translation text to SDL Trados, to connect the translation memory data base and terminological base which were provided by the teacher.

\subsection{Ancillary Analyses}

Of the whole group, only two students could not pass the lower limit of the "satisfactory" grade, showing a learning rate of 0.50 and 0.60 respectively $(16.67 \%)$. Two students managed to cross the lower limit of the "excellent" grade with a learning rate of 0.90 and $0.92(16.67 \%)$. The rest of the students demonstrated a learning rate in the range 0.70-0.78 (66.66\%), which is a sufficient level according to V.P. Bespalko, 1989.

A mid-term assessment was conducted at the eighth lesson and in its content was similar to the pre-experimental assessment. Excerpts from "Optional Protocol to the Convention against Torture and other Cruel, Inhuman or Degrading Treatment or Punishment” agreement were used during the preparation of the assessment materials. While 
translating an excerpt using the SDL Trados translation automation system, the students used the same translation memory data base that they used while carrying out the pre-experimental assessment.

In general, the results of handwritten works cannot be considered as satisfactory and so the question is why, demonstrating a proper increase in translation using a translation automation system, the students have hardly progressed in written translations of the same subject but writing by hand? It can be suggested that the answer is in the motivational component; more precisely it is in its absence in the case of a handwritten task. During the semester, the students constantly complained about the need for handwritten translation and asked to remove this type of tasks from the content of the test work.

Even the possibility to obtain an additional grade, which could theoretically improve their overall result, was not too stimulating. It should be pointed out that most of the fifth-year students had already had a job, so their motivational incentives changed. As an employer did not require a diploma with excellent grades, and instead there was a need to have a translation automation system possession, therefore, right the opportunity to master them motivated the students greatly both to attend classes and to do their homework and tests using exactly translation automation systems.

And though the students sometimes noted that translations were difficult and homework took too much time, especially considering the need to attend a university computer class to complete them, they still agreed that they were useful and the execution of the tasks of such volumes favorably influenced on the skills for using a translation automation system.

An average student learning rate while doing the translation using SDL Trados is 0.82 , and therefore, the hypothesis formulated by us before the start of the experimental study was confirmed. Out of all the students only the three students (Student 3,6 and 12) did not manage to reach a satisfactory level of learning capability and their rates were $0.60,0.62$ and 0.52 respectively. However, it should be added that the results of these students were among the weakest in the pre-experimental and mid-term assessments. The result of Student 6 increased comparing to the pre-experimental assessment from 0.50 to 0.62 , while the results of Student 3 and 12 decreased slightly: of Student 3 -from 0.72 to 0.60 , of Student 12 -from 0.60 to 0.52 .

\subsection{Participant Flow}

Most likely this situation can be explained by the low initial level of the mentioned students. It was very difficult for these students to perform complicated and large-volume tasks, that is why they often did not have time to do their homework at all or did it partially. However, the students clearly understood the need to study translation automation systems, so they did not lose inspiration, attended classes and finally passed the SDL Trados certification exam. One student (Student 1) reached the upper limit of the "satisfactory" grade with a learning rate of 0.78 and one more student (Student 9) reached the lower limit of the "good" grade (a learning rate of 0.80), the rest of the students showed excellent results and their learning capability rate ranged from 0.90 to 0.96 .

The increase in the learning rate of the acquired level of skills formation and skills for handwritten translation and translation using translation automation systems from English into Ukrainian is shown in Table 2.

Table 2. Comparative table of the average indexes of pre- and post- experimental assessments to determine the effectiveness of the module "Modern Translation Technologies. Translation Automation Systems" in the group

\begin{tabular}{|c|c|c|c|c|c|}
\hline \multicolumn{3}{|c|}{ Handwritten translation } & \multicolumn{3}{|c|}{$\begin{array}{l}\text { Handwritten translation using translation automation } \\
\text { system (SDL Trados) }\end{array}$} \\
\hline $\begin{array}{c}\text { Learning } \\
\text { capability rate } \\
\text { (pre- } \\
\text { experimental } \\
\text { assessment) }\end{array}$ & $\begin{array}{l}\text { Learning capability } \\
\text { rate(mid-term } \\
\text { post-experimental } \\
\text { assessment) }\end{array}$ & Increase & $\begin{array}{l}\text { Learning capability } \\
\text { rate } \\
\text { (pre-experimental } \\
\text { assessment) }\end{array}$ & $\begin{array}{l}\text { Learning capability } \\
\text { rate (mid-term } \\
\text { post-experimental } \\
\text { assessment) }\end{array}$ & Increase \\
\hline 0,64 & 0,68 & 0,04 & 0,74 & 0,82 & 0,08 \\
\hline
\end{tabular}

Comparison of averages of students before and after the first semester of experimental training shows a slight increase in the level of learning in handwritten translation, while the increase in translation using the translation automation system can be called significant, especially given that before experimental training students did not have the skills and abilities to use the mentioned system. This allows us to talk about the effectiveness of our module 
"Modern translation technologies. Translation automation systems".

Avoid hyphenation at the end of a line. Symbols denoting vectors and matrices should be indicated in bold type. Scalar variable names should normally be expressed using italics. Weights and measures should be expressed in SI units.

In order to substantiate the conclusions and verify the reliability of the data obtained during the training in the experimental group - EG-1A (the first semester of training under option A), we evaluated them using mathematical statistics.

Let's formulate hypotheses:

HO - differences in the values of the trait (increase) between the results of pre-experimental (sample 1) and intermediate post-experimental (sample 2) sections, which are obtained during experimental training, are not statistically significant;

H1 - differences in the values of the trait (increase) between the results of pre-experimental (sample 1) and intermediate post-experimental (sample 2) sections, which are obtained during the experimental training, are statistically significant.

Let's find the arithmetic mean for each series of values of M1 and M2: M1 $=0.74 ; \mathrm{M} 2=0.82$.

Let's determine the average difference between the values of $\mathrm{Md}=-0.09$.

Standard deviation: $\mathrm{Ad}=0.117$, empirical value of the t-criterion: $\mathrm{Temp}=2.57$.

Number of degrees of freedom: $\mathrm{df}=\mathrm{n}-1=11$.

The critical value of $\mathrm{t}$ for this df: $2.201<\mathrm{Tcr}<3.106$.

This result can be interpreted ambiguously. Thus, depending on the importance of the problem, the researcher may consider the obtained statistical estimate reliable at the level of 5\%, and thus accept hypothesis $\mathrm{H} 1$, rejecting hypothesis $\mathrm{H} 0$, or - unreliable at the level of $1 \%$, thereby rejecting hypothesis $\mathrm{H} 1$ and accepting hypothesis $\mathrm{H} 0$. Given that in our case, in fact, the initial level of students was zero, because before the experiment students did not learn to translate in writing using translation automation systems, so we actually compared the results of the first intermediate (used as a pre-experimental) section and intermediate post-experimental section, we consider it appropriate to state that in this case the hypothesis $\mathrm{H} 1$ is accepted. Accordingly, the differences in the values of the trait (increase) between the results of pre-experimental (sample 1) and intermediate post-experimental (sample 2) sections obtained during experimental training are statistically significant.

Summarizing the above, we can conclude that the results of statistical processing confirm the correctness of the pedagogical experiment and the reliability of the data obtained during it.

It should also be added that during the classes the students actively expressed their positive attitude to the module "Modern Translation Technologies. Translation Automation Systems." They constantly asked why such a module had not been introduced before, as possessing translation automation systems could make it much easier to complete many tasks which they received during the studies, in particular, to do a practical training, to write a course work (one chapter of which should include a text translation with a volume from 10 up to 20 thousand printed characters without spaces), to do homework tasks in translation practice. Besides that, the students mastered the basics of using translation automation systems very easily, constantly expressing a desire to master larger number of such systems. Having mastered the three systems, they already began to compare them, critically evaluating the functionality and convenience of their use

Most of the students were pleased with a cloud-based translation automation system that does not have a powerful set of options as, let us say, SDL Trados or MemoQ, but at the same time it is simpler and more convenient to use and also contains a free account which, though is limited in volume, but is sufficient for the students to use at this stage. During the breaks, the teacher repeatedly had to watch how the students were carrying out the tasks in translation practice using Memsource translation automation system on their own laptops.

Some students even moved on, became familiar with the information on available translation automation systems at the market and mastered the SmartCAT system, which is cloud-based, not less convenient in use than Memsource, but, in addition, is completely free of charge in usage. The students constantly asked questions about the existing software for translators and expressed their desire to master it. One should also admit that the attendance of the lessons be the students was at a high level which is also an evidence of the high motivation of the students and their desire to master modern translation technologies. 
Therefore, the received results of the experimental training indicate that the hypothesis, formulated before its execution, was confirmed: the use of the translation automation systems according to the developed methods allows to significantly improve the efficiency of a written translation of future translators both qualitatively (achieving a learning rate not less than 0.80) and quantitatively (translating texts of a larger volume at the same period of time) and all the training options developed by us for the module" Modern Translation Technologies. Translation Automation Systems" are, in fact, equally effective and may be recommended for implementation at Translation Departments of higher educational institutions within the academic discipline of "Translation Theory and Practice".

As part of our research, we did not develop an additional test to check the theoretical aspect because the requirement of the CAT for GRAD project was a free certification exam taken by students from the manufacturer of translation automation SDL Trados at the end of the first semester. This test consists of 40 questions divided into four sections of 10 questions each. The test time is 40 minutes, 10 minutes for each section. Students take the test online in a university computer class under the supervision of a teacher. The passing score was 30 correct answers out of 40 . Students were extremely motivated to take the certification exam because first it costs a lot of money and now it was a possibility to pass it for free. Secondly, based on the results of the exam, a personal online certificate from SDL Trados is issued. In the theoretical module "Factors of successful employment of a translator in the specialty" students learned that the link to the mentioned certificate can be attached to their resumes on relevant job search resources for translators (a list of such resources is given in the manual "Factors of successful employment of a translator in the specialty". the fact that the use of translation automation systems, as we have already mentioned, is a mandatory requirement of employers, and the fact that Trados occupies a leading position among the developers of such software, students understood the benefits of passing the exam for their future careers. Given that the use of translation automation systems, as we have already mentioned, is a mandatory requirement of employers, as well as the fact that Trados occupies a leading position among the developers of such software, students understood the benefits of passing the exam for their future career.

\section{Discussion}

Experimental work was organized during 2013-2018 at the three stages of scientific-pedagogical search (analytically-stating, forming, final) on the basis of higher educational institutions of Ukraine.

Generalization of the results of the analytical and stating stage of the experimental study showed that in the development of the professional competence of Masters-translators by the means of ICT a low level dominates. Questionnaires, conducted among the Masters-translators, give reasons to record their dissatisfaction in the state of vocational training and the desire to modernize it by updating the content of academic disciplines, providing students with up-to-date information, ensuring the practical orientation of vocational training and elimination of excessive theorization of the educational process.

Responding to the questionnaire, the representatives of the translation industry expressed negative attitude to the current level of training of Masters-translators in HEI, emphasized the urgent need to introduce translation technologies into the structure of training, strengthen the development of personal competence of Masters-translators. In general, the respondents, HEI teachers preparing Masters-translators, positively evaluated the state of training but found it desirable to update the educational and methodical complex (EMC), to introduce effective systems of exercises for teaching oral and written translation, to improve the independent work of Masters-translators using the means of ICT. The received results made it possible to give a reason for pedagogical conditions for the development of the professional competence of Masters-translators by the means of ICT and to create a pedagogical system, the effectiveness of which as tested during the forming stage of the pedagogical experiment.

The conducted research does not exhaust a wide range of relevant issues of professional training of future translators. Among the prospects for the further exploration the following ones were marked: theoretical and methodical substantiation of the development of professional competence of Masters-translators in experience; development of theoretical and practical foundations of distant training of Masters-translators; study of theoretical and methodological bases of formation of professional competence of a teacher who trains Masters-translators by the means of ICT; theoretical and methodical foundations of the professional development of translators in the system of continuing education using ICT.

Theoretical research and experimental verification of the pedagogical system of development of professional competence of Masters-translators by the means of ICT allowed to formulate the following methodical recommendations.

Based on the experience of the developed countries and the requirements formulated in the framework of the project 
of the European Translators Training at the level of Magistration EMT (European Master's in Translation) (Torres-Simón, E., \& Pym, A. (2019)), we recommend to introduce the module "Modern Translation Technologies. Translation Automation Systems" at Master's level of training.

Authors recommend selecting several desktop programs and at least one cloud-based which are becoming more and more popular at the market and offer a convenient alternative to desktop versions. In our case, the module materials are proposed to be processed using two desktop systems of translation automation SDL Trados and MemoQ and one cloud-based system Memsource. All of the mentioned programs are market leaders and are popular both with translation companies and freelance translators and have been recommended for studying by translation industry representatives.

It is not advisable to study the powerful functionality of the mentioned programs to the maximum extent as it takes too much time. In addition, even industry representatives admit that they do not use all of the options or use some options so seldom that they cannot even immediately remember where such option is. Providing the basics of use of the mentioned systems allows students to develop the ability to self-education and, in case of the need, they can easily master new necessary options. That is why within the module all functionality should be limited only to the basic options dividing them by thematic blocks, in particular,(the list is given according to the principle of gradual increase of difficulties): 1-translation of documents of different formats by the means of SDL Trados, MemoQ, Memsource (we chose the most common formats: Word, Excel, Power Point, pdf); 2-creation of terminological databases by the means of SDL Trados, MemoQ, Memsource and managing them; 3-creation of translation memory bases on the ground of the previously translated document (alignment) by the means of SDL Trados, MemoQ, Memsource and managing them; 4-implementation of translation project in SDL Trados, MemoQ, Memsource systems.

Distribution of the educational information of the module can be carried out in several ways which may differ in the number of scheduled training hours and the structure of the educational information presentation from a certain system of translation automation (Guo, Y., Guan, Y., Yang, X., Xu, J., Zhou, X., She, Z., ... \& Pan, Z. (2014)). In our study we offer three types of such distribution which turned to be equally effective according to a result of the conducted experimental training.

The presence of a large part of the texts of the mentioned agreements in the official translation into the Ukrainian language allows a teacher to quickly compile such supporting materials for students as translation memory base, terminological base and even, if necessary, autosuggest dictionaries which students can use while executing the tasks from the module. In particular, it is recommended to assume the three basic human rights agreements as a basis of the mentioned supporting materials: "Universal Declaration of Human Rights", "International Covenant on Civil and Political Rights" and "International Covenant on Economic, Social and Cultural Rights". During the preparation of the module a slight modification of the original texts is allowed, for example, intentional repetition of the same fragment for several times and so on.

The independent work of students on the module should maximally simulate the real translation activity and, therefore, it is possible to recommend giving texts of large volumes for independent work at home, translating which students will use translation memory bases and terminological bases provided by a teacher and created on their own in the course of the lessons on the created module which will accustom them to the daily work of a practicing translator.

\section{References}

Bravenboer, D., \& Lester, S. (2016). Towards an integrated approach to the recognition of professional competence and academic learning. Education+ Training. https://doi.org/10.1108/ET-10-2015-0091

Cuminatto, C., Baines, R., \& Drugan, J. (2017). Employability as an ethos in translator and interpreter training. The Interpreter and Translator Trainer, 11(2-3), 123-138. https://doi.org/10.1080/1750399X.2017.1350899

DeGrande, H., Liu, F., Greene, P., \& Stankus, J. A. (2018). Developing professional competence among critical care nurses: An integrative review of literature. Intensive and Critical Care Nursing, 49, 65-71. https://doi.org/10.1016/j.iccn.2018.07.008

Gardulf, A., Nilsson, J., Florin, J., Leksell, J., Lepp, M., Lindholm, C., ... \& Johansson, E. (2016). The Nurse Professional Competence (NPC) Scale: Self-reported competence among nursing students on the point of graduation. Nurse education today, 36, 165-171. https://doi.org/10.1016/j.nedt.2015.09.013

Guo, Y., Guan, Y., Yang, X., Xu, J., Zhou, X., She, Z., ... \& Pan, Z. (2014). Career adaptability, calling and the 
professional competence of social work students in China: A career construction perspective. Journal of Vocational Behavior, 85(3), 394-402. https://doi.org/10.1016/j.jvb.2014.09.001

Hachfeld, A., Hahn, A., Schroeder, S., Anders, Y., \& Kunter, M. (2015). Should teachers be colorblind? How multicultural and egalitarian beliefs differentially relate to aspects of teachers' professional competence for teaching in diverse classrooms. Teaching and Teacher Education, 48, 44-55. https://doi.org/10.1016/j.tate.2015.02.001

Hakim, A. (2015). Contribution of competence teacher (pedagogical, personality, professional competence and social) on the performance of learning. The International Journal of Engineering and Science, 4(2), 1-12. URL: https://www.theijes.com/papers/v4-i2/Version-3/A42301012.pdf

Heydari, A., Kareshki, H., \& Armat, M. R. (2016). Is nurses' professional competence related to their personality and emotional intelligence? a cross-sectional study. Journal of Caring Sciences, 5(2), 121. https://doi.org/10.15171/jcs.2016.013

Huang, R., Su, H., \& Xu, S. (2014). Developing teachers' and teaching researchers' professional competence in mathematics through Chinese Lesson Study. ZDM, 46(2), 239-251. https://doi.org/10.1007/s11858-013-0557-8

Lauermann, F., \& König, J. (2016). Teachers' professional competence and wellbeing: Understanding the links between general pedagogical knowledge, self-efficacy and burnout. Learning and Instruction, 45, 9-19. https://doi.org/10.1016/j.learninstruc.2016.06.006

Lester, S. (2014). Professional competence standards and frameworks in the United Kingdom. Assessment \& Evaluation in Higher Education, 39(1), 38-52. https://doi.org/10.1080/02602938.2013.792106

Li, X. (2018). Self-assessment as 'assessment as learning'in translator and interpreter education: Validity and $\begin{array}{lllll}\text { washback. The Interpreter and Translator } & \text { Trainer, }\end{array}$ https://doi.org/10.1080/1750399X.2017.1418581

Mulder, M. (2014). Conceptions of professional competence. In International handbook of research in professional and practice-based learning (pp. 107-137). Springer, Dordrecht. https://doi.org/10.1007/978-94-017-8902-8

Numminen, O., Laine, T., Isoaho, H., Hupli, M., Leino-Kilpi, H., \& Meretoja, R. (2014). Do educational outcomes correspond with the requirements of nursing practice: educators' and managers' assessments of novice nurses' professional competence. Scandinavian journal of caring sciences, 28(4), 812-821. https://doi.org/10.1111/scs.12115

Rahman, M. H. (2014). Professional competence, pedagogical competence and the performance of junior high school of science teachers. Journal of Education and Practice, 5(9), 75-80. URL: file://C:/Users/User/AppData/Local/Temp/11868-14215-1-PB.pdf

Robert, I. S., Remael, A., \& Ureel, J. J. (2017). Towards a model of translation revision competence. The Interpreter and Translator Trainer, 11(1), 1-19. https://doi.org/10.1080/1750399X.2016.1198183

Shen-Miller, D. S., Schwartz-Mette, R., Van Sickle, K. S., Jacobs, S. C., Grus, C. L., Hunter, E. A., \& Forrest, L. (2015). Professional competence problems in training: A qualitative investigation of trainee perspectives. Training and Education in Professional Psychology, 9(2), 161. https://doi.org/10.1037/tep0000072

Tang, F., \& Li, D. (2017). A corpus-based investigation of explicitation patterns between professional and student interpreters in Chinese-English consecutive interpreting. The Interpreter and Translator Trainer, 11(4), 373-395. https://doi.org/10.1080/1750399X.2017.1379647

Tiselius, E., \& Hild, A. (2017). 23 Expertise and Competence in Translation and Interpreting. The handbook of translation and cognition, 425. https://doi.org/10.1002/9781119241485.ch23

Torres-Simón, E., \& Pym, A. (2019). European Masters in translation. The Evolving Curriculum in Interpreter and Translator Education: Stakeholder perspectives and voices. https://doi.org/10.1075/ata.xix.04tor 


\section{Appendix A.}

\section{QUESTIONNAIRE}

The use of cloud technologies in educational activities

Purpose: to find out the state and level of formation of information and communication competence in the use of cloud technologies.

Instructions: please choose the answer that best corresponds to reality and your state; try to answer as objectively as possible and evaluate your abilities.

Please indicate the name of the institution where you study

1. Do teachers propose you to use cloud technology services in the learning process?

1 no; $\square 2 ; \square 3 ; \square 4 ; \square 5$ propose constantly

2. To what extent do you use publicly available cloud services in the learning process?

1 I do not use; $\square 2 ; \square 3 ; \square 4 ; \square 5$ use constantly

3. To what extent do you use corporate cloud services in the learning process?

1 I do not use; $\square 2 ; \square 3 ; \square 4 ; \square 5$ use constantly

4. How often do teachers use the "digital results" you get when working on computer equipment as proof of your success?

1 I do not use; $\square 2$; $\square 3$; $\square$; $\square 5$ use constantly

5. How often do teachers use cloud technology tools to track and evaluate the state of your academic achievements?

1 do not use; $\square 2$; $\square 3$; $\square 4 ; \square 5$ use constantly

6. How often do you use cloud technology in your independent work?

1 I do not use; $\square 2 ; \square 3 ; \square 4 ; \square 5$ use constantly

7. How often do you use cloud technology when working in groups?

1 I do not use; $\square 2$; $\square 3$; $\square$; $\square 5$ use constantly

8. How often do you use cloud technology to find solutions to specific problems?

1 I do not use; $\square 2 ; \square 3 ; \square 4 ; \square 5$ use constantly

9. To what extent do you use cloud technology for programming, software development in the learning process?

1 I do not use; $\square 2 ; \square 3 ; \square 4 ; \square 5$ use constantly

10. To what extent do you use cloud-based software when working in the classroom?

1 I do not use; $\square 2 ; \square 3 ; \square 4 ; \square 5$ use constantly

11. To what extent do you use cloud-based software in extracurricular activities?

1 I do not use; $\square 2 ; \square 3 ; \square 4 ; \square 5$ use constantly

\section{Copyrights}

Copyright for this article is retained by the author(s), with first publication rights granted to the journal.

This is an open-access article distributed under the terms and conditions of the Creative Commons Attribution license (http://creativecommons.org/licenses/by/4.0/). 